\title{
A cabinet for the detection of fluorescent bacterial cultures
}

\author{
E. J. L. LOWBURY, H. A. LILly, AND M. D. WILKINS \\ From the Medical Research Council Industrial Injuries and Burns Research Unit, \\ Birmingham Accident Hospital
}

SYNOPSIS A cabinet for detecting the fluorescence of cultures on agar media is described.

The use of fluorescence as a criterion for detection of Ps. pyocyanea is compared with that of the oxidase reaction. From a series of patients with burns, all colonies of Gram-negative bacilli which gave a positive oxidase reaction yielded fluorescent subcultures on $0.03 \%$ cetrimide agar; all fluorescent cultures on cetrimide agar gave a positive oxidase reaction, but a few mixed cultures which fluoresced on blood agar were not picked for oxidase tests because the colonies of Ps.pyocyanea were overgrown by other bacteria. Out of 1,812 swabs which yielded fluorescent subcultures on $0.03 \%$ cetrimide agar, $1,739(96 \%)$ showed strong characteristic fluorescence on the initial blood agar plate culture.

Examination of cultures on some solid media for fluorescence under ultra-violet irradiation has proved useful in the detection of Pseudomonas pyocyanea (Lowbury, 1951). We describe here a cabinet suitable for the inspection of cultures under ultra-violet irradiation, and report a comparison of its use with that of the oxidase reaction (Kovacs, 1956) in the study of Gram-negative bacilli from burns.

\section{THE CABINET}

The design and measurements of the cabinet are shown in Figs. 1 and 2. It consists of a wooden box containing the ultra-violet lamp, with a door on one side to admit a culture plate, and a window on a projection from one end of the roof through which the irradiated plate can be inspected. The box is divided into lower and upper compartments, the lower containing (for A.C. mains) a capacitor $(10 \mu \mathrm{F}$., Griffin and George $S 31-462 / 10)$ and choke (S 31-462/05), and the upper containing an ultraviolet lamp (125 watts, 3-pin cap, $\mathrm{S} 31-460)$ in a special lamp holder (S 31-462120) and a screen to shield the inspection window from the direct incidence of ultraviolet irradiation; for D.C. mains a resistance (S 31$462 / 15$ ) is needed in place of the capacitor and choke. The walls of the upper chamber are painted black. The opening to admit culture plates for inspection is placed under and to one side of the ultra-violet lamp, and has a sliding door. The inspection window has a retractable glass pane about 2 in. deep to the outer frame; the frame is lined with Sorbo rubter and curved to accommodate the forehead and nose. The box is provided with a

Received for publication 4 December 1961 . switch and a pilot light, and ventilated by seven holes ( 1 in. diameter) on each side of the lower chamber, six holes in the partition, and four louvres ( $3 \frac{1}{2}$ by $\frac{1}{2}$ in.) in the roof. The floor carrying the capacitor and choke is attached at one end to the wall carrying the lamp holder. The whole of this section is separate and can be pulled out from a shell consisting of the remaining walls, the roof of the cabinet, and the partition between upper and lower compartments. The separated components are shown in the photograph (Fig. 3).

An interval of two or three minutes is allowed between switching on the lamp and using it for the detection of fluorescence. A culture plate is then inserted through the door and placed under the lamp; the door is closed and the plates are examined through the inspection window, the eyes being held close to the window.

\section{COMPARISON OF FLUORESCENCE AND THE OXIDASE REACTION IN THE RECOGNITION OF PS. PYOCYANEA}

Kovacs (1956) reported the use of the oxidase reaction as a simple and rapid screening test for Ps. pyocyanea. We have compared this method with an examination for fluorescence of growth on blood agar and of subcultures on $0.03 \%$ cetrimide agar, a selective medium for Ps. pyocyanea (Lowbury and Collins, 1955), in the study of bacteria from burns.

METHODS Cultures of swabs from burns on horse blood agar plates (prepared with infusion broth and with $4 \%$ New Zealand agar) were examined, after overnight incubation at $37^{\circ} \mathrm{C}$., for oxidase and for fluorescence. 

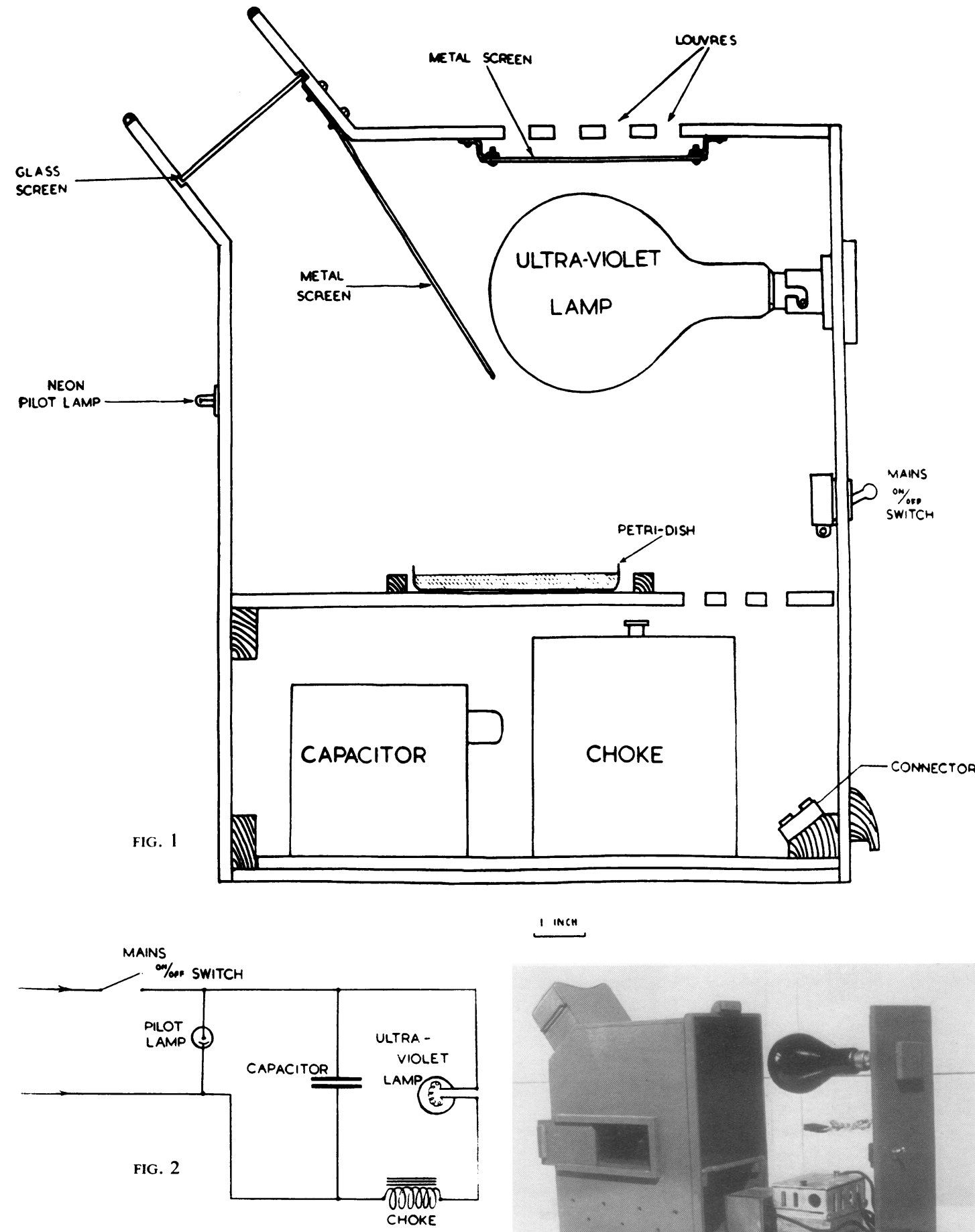

FIG. 1. Diagram of a sectional view of the ultra-violet cabinet.

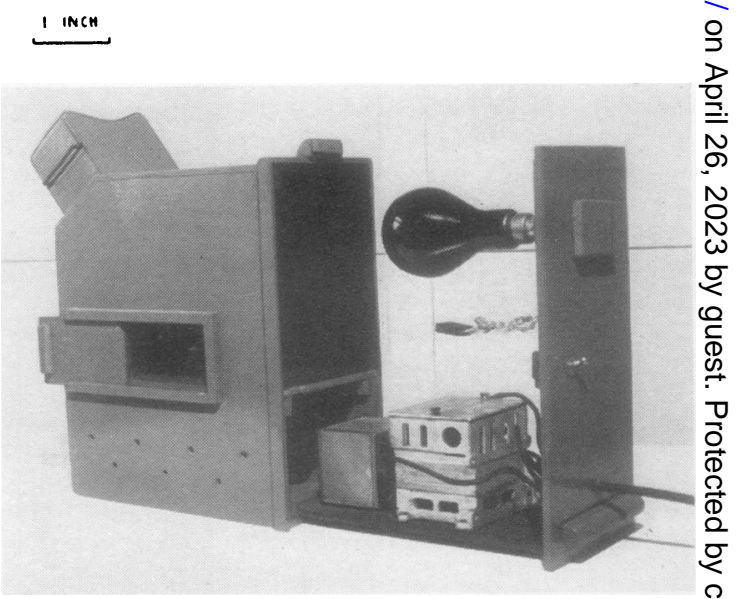

FIG. 2. Wiring diagram of the ultra-violet cabinet for A.C. mains.

FIG. 3. Photograph of the cabinet with the floor section pulled out from the shell. 
From every plate-culture, one colony of each type showing the appearances of Gram-negative bacilli (except those with smooth convex or mucoid cultures typical of Klebsiella aerogenes) was picked with a straight platinum wire and rubbed on to filter paper saturated with $1 \%$ tetramethyl-para-phenylene-diamine-dihydrochloride; a positive oxidase reaction was recorded when deep purple colour appeared in less than 10 seconds. The same plates were examined for green, blue-green or yellowgreen fluorescence under ultra-violet irradiation. Colonies tested for oxidase were subcultured on $0.03 \%$ cetrimide agar, which was examined after overnight incubation for growth, pigmentation, and fluorescence.

Cultures which showed no fluorescence either on blood agar or on subculture to cetrimide agar, and those which failed to give a positive oxidase reaction, were tested for urease production (Cook, 1948) and phenyl pyruvic acid reaction (Henriksen, 1950); those which were negative by these tests were examined for methyl red and Voges Proskauer reactions, citrate utilization, and fermentation of glucose, mannite, lactose, and sucrose.

The following selection of strains of Gram-negative bacilli from the National Collection of Type Cultures was examined for oxidase reaction and fluorescence: Citrobacter (6266, 6267, 9645, and 7229), Klebsiella pneumoniae (8172), Proteus vulgaris (401), Proteus morganii (417), Proteus rettgeri (7447), Proteus mirabilis (4199), Escherichia coli (9002), and Alkaligenes (415).

RESULTS Some parts of a culture of Ps. pyocyanea on blood agar, in particular the centre of an area of confluent growth, or single colonies when very few were present, sometimes fluoresced poorly and occasionally showed no fluorescence; but the great majority of cultures of Ps. pyocyanea showed vivid and characteristic fluorescence on blood agar, and all colonies which showed a positive oxidase reaction, whether or not they fluoresced on blood agar, grew and showed typical fluorescence on $0.03 \%$ cetrimide agar. It has been shown (Hurst and Lowbury, 1952) that fluorescin diffuses from $P$ s. pyocyanea through agar media and is picked up by neighbouring growth of coliform bacilli and some other organisms, which may then fluoresce more brilliantly than the growth of Ps. pyocyanea; this happens especially when the strain of Ps. pyocyanea is one which produces much pyocyanin, which reduces the brilliance of fluorescence but gives it a characteristic green colour. Fluorescence in a mixed culture is therefore not an indication that a particular colony is Ps. pyocyanea, but it shows that $P$ s. pyocyanea is growing on the plate and was present in the material inoculated.

Table I shows the growth and fluorescence on $0.03 \%$ cetrimide agar of 517 cultures of Gramnegative bacilli from burns, subcultured from single colonies on blood agar, and the oxidase reaction of the same colonies tested from blood agar; all the colonies which fluoresced gave a positive oxidase
TABLE I

GROWTH AND FLUORESCENCE OF 517 GRAM-NEGATIVE BACILLI FROM BURNS SUBCULTURED TO CETRIMIDE AGAR COMPARED WITH OXIDASE REACTIONS OF SAME STRAINS

\begin{tabular}{lcc}
$\begin{array}{l}\text { Growth and } \\
\text { Fluorescence of Sub- } \\
\text { culture on Cetrimide }\end{array}$ & \multicolumn{2}{l}{ Colonies on Blood Agar Showing } \\
\cline { 2 - 3 } \begin{tabular}{l} 
Agar \\
\cline { 2 - 3 }
\end{tabular} & Oxidase + Reaction & Oxidase - Reaction \\
\hline+ & 318 & 0 \\
& 0 & 199
\end{tabular}

reaction, and all of those which did not fluoresce gave a negative oxidase reaction.

Table II shows a comparison of fluorescence on the primary blood agar culture and on the subculture of Gram-negative bacilli to $0.03 \%$ cetrimide agar in an examination of 4,741 swabs from burns. Fluorescence on cetrimide agar was shown by 1,812 cultures, and of these $1,739(96 \%)$ had shown vivid fluorescence on the original blood agar: the remaining $4 \%$ of strains included many which showed less vivid fluorescence on blood agar and required confirmation, either by the oxidase reaction or by subculture to cetrimide agar, before a presumptive diagnosis of Ps. pyocyanea could be reported.

\section{TABLE II}

FLUORESCENCE OF GROWTH ON BLOOD AGAR CULTURE OF 4,741 BURN SWABS AND ON SUBCULTURE OF GRAMNEGATIVE BACILLI TO CETRIMIDE AGAR

\begin{tabular}{ll} 
Medium & $\begin{array}{l}\text { No. of Cultures Showing Typical } \\
\text { Fluorescence }\end{array}$ \\
\hline Blood agar (primary culture) & 1,739 \\
Cetrimide $(0 \cdot 03 \%$ ) agar (subculture) & 1,812
\end{tabular}

In a series of 122 blood agar cultures (see Table III) which were examined in parallel by oxidase tests on selected colonies and by fluorescence of the whole culture, strong and typical fluorescence was seen in 59 out of 73 of the plates from which oxidase-positive colonies were picked, but some fluorescence was detected in all of these 73 plates. Fluorescence was

\section{TABLE III}

FLUORESCENCE AND OXIDASE REACTION OF GROWTH ON BLOOD AGAR PLATE CULTURES OF BURNS YIELDING GRAMNEGATIVE BACILLI

\begin{tabular}{|c|c|c|c|}
\hline \multirow{2}{*}{$\begin{array}{l}\text { Fluorescence of } \\
\text { Growth }\end{array}$} & \multicolumn{3}{|c|}{ No. of Plates from which were Isolated } \\
\hline & $\begin{array}{l}\text { Oxidase + } \\
\text { Colonies }\end{array}$ & $\begin{array}{l}\text { Oxidase - } \\
\text { Colonies }\end{array}$ & $\begin{array}{l}\text { Not Tested for } \\
\text { Oxidase }\end{array}$ \\
\hline $\begin{array}{l}\text { Strong and typical } \\
\text { Weak or doubtful } \\
\text { Absent }\end{array}$ & $\begin{array}{r}59 \\
14 \\
0\end{array}$ & $\begin{array}{r}0 \\
0 \\
38\end{array}$ & $\begin{array}{l}5 \\
0 \\
6\end{array}$ \\
\hline
\end{tabular}

${ }^{1}$ On these plates cultures were mixed with no typical colonies visible. 
absent from all of the 38 cultures in which no oxidase-positive colonies were detected. Oxidase tests were not made on 11 plates, which did not show typical colonies of Gram-negative bacilli, but five of these showed colonies of typical fluorescence in areas of mixed culture, subculture of which on to $0.03 \%$ cetrimide agar yielded typical growth of Ps. pyocyanea.

Of 303 strains which did not show typical fluorescence or oxidase reaction, 31 were classified as Escherichia, 26 as Citrobacter, 114 as Proteus, and 132 as Providencia. Of the strains of Escherichia, Klebsiella, Citrobacter, Proteus, and Alkaligenes from the National Collection of Type Cultures, only Alkaligenes showed a strong oxidase reaction; none of these strains gave green, blue-green or yellowgreen fluorescence.

\section{COMMENTS}

Examination of blood agar cultures for fluorescence under ultra-violet irradiation is a simple method which allows immediate recognition and presumption of Ps. pyocyanea in the great majority of cultures of this organism without picking of colonies. The small proportion of cultures of Ps. pyocyanea which did not, in our experience, fluoresce on primary blood agar culture showed typical fluorescence on subculture to cetrimide agar. This medium, which is also selective for Ps. pyocyanea, makes it possible to use the production of pyocyanin, which is produced by a proportion of strains, as a criterion for the recognition of Ps. pyocyanea; if made up with cetrimide marketed since 1953 the medium should contain $0.03 \%$ of cetrimide (Lowbury and Collins, 1955) not $0.1 \%$, which was found to be the optimum concentration with earlier and less strongly bacteriostatic batches of cetrimide (Lowbury, 1951).

The value of the oxidase reaction as a taxonomic test has recently been discussed by Steel (1961). Among the Gram-negative bacilli, Pseudomonas is exceptional in giving a prompt positive oxidase

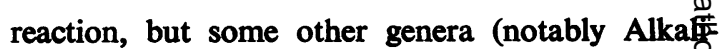
genes) may also give positive reactions. The oxidase reaction has the advantage of being found in individual colonies, some of which may not fluoresge on blood agar, and of appearing in cultures of

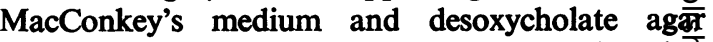
(which give poor fluorescence or none). On the oth क्ष hand, it is a much slower test than examination of blood agar plates for fluorescence, and smál numbers of Ps. pyocyanea are more easily picked oụt from mixed culture with staphylococci and coliform bacilli by fluorescence than by picking colonies for oxidase tests; for this reason Ps. pyocyanea may sometimes be detected by fluorescence when inspection followed by oxidase tests fails to reveal theif presence.

The two methods can, with convenience ang advantage, be used together, suspected cultures on blood agar being screened for fluorescence, aftêr which the non-fluorescent cultures are tested for oxidase production as an alternative to subculture on cetrimide agar.

Fluorescence may be weak or absent in growth plates with a very thin layer of culture medium. We have noticed also that cultures kept in the refrigeretor tend to lose their fluorescence but regain it whine standing at room temperature. Iridescent cultures have tended to be less strongly fluorescent on blogi agar than those which showed no iridescence Strains which produce much pyocyanin fluoresळ્e less brilliantly, but with a characteristic green glow.

We are grateful to Dr. J. P. Bull for helpful suggestions

\section{REFERENCES}

Cook, G. T. (1948). J. Path. Bact., 60, 171.

Henriksen, S. D. (1950). J. Bact., 60, 225.

Hurst, L., and Lowbury, E. J. L. (1952). J. clin. Path., 5, 359.

Kovacs, N. (1956). Nature (Lond.), 178, 703.

Lowbury, E. J. L. (1951). J. clin. Path., 4, 66.

-, and Collins, A. G. (1955). Ibid., 8, 47.

Steel, K. J. (1961). J. gen. Microbiol., 25, 297. 